Supplement of Geosci. Model Dev., 11, 2857-2873, 2018

https://doi.org/10.5194/gmd-11-2857-2018-supplement

C Author(s) 2018. This work is distributed under

the Creative Commons Attribution 4.0 License.

(c) (1)

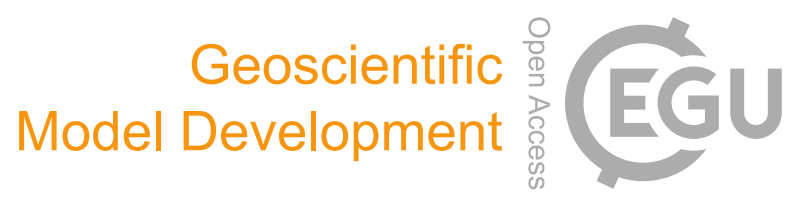

Supplement of

\title{
Vegetation distribution and terrestrial carbon cycle in a carbon cycle configuration of JULES4.6 with new plant functional types
}

Anna B. Harper et al.

Correspondence to: Anna B. Harper (a.harper@exeter.ac.uk)

The copyright of individual parts of the supplement might differ from the CC BY 4.0 License. 
Description of new calculations for leaf, root, and wood nitrogen

As mentioned in Section 2.3 of the main text, there are four changes to JULES between the 9 PFT version presented in (Harper et al., 2016) and in this manuscript. Here we describe the impacts of changes to leaf, root, and wood nitrogen.

There are 4 comparisons made:

1. CRM5: canopy radiation model $=5$ (using the default $k_{\mathrm{n}}=0.78$ )

2. CRM5+N Traits: As in 1 but with the new stem and $\operatorname{root} \mathrm{N}\left(k_{\mathrm{n}}=0.78\right)$

3. CRM6: canopy radiation model $=6$, trait $\_$phys $=$True $\left(k_{\mathrm{nl}}=0.2\right)$

4. CRM6+N Traits: As in 3 but with the new stem and $\operatorname{root} \mathrm{N}\left(k_{\mathrm{nl}}=0.2\right)$

In CRM5, leaf $\mathrm{N}$ for canopy layer $i$ (in a canopy with 10 layers) is calculated as:

$$
N_{\text {leaf }_{i}}=N_{m} * L M A * e^{-k_{n} * \frac{i-1}{10}} \quad \text { Eq. A1 }
$$

where $N_{\mathrm{m}}$ is leaf nitrogen per unit mass $\left(\mathrm{kg} \mathrm{kg}^{-1}\right)$ at the top of the canopy, LMA is leaf mass per unit area $\left(\mathrm{kg} \mathrm{m}^{-2}\right)$ at the top of the canopy, and $k_{\mathrm{n}}$ is a decay coefficient. JULES assumes that cumulative leaf area index $(L)$ is divided evenly between the canopy layers, so Eq. A1 is equivalent to:

$$
N_{\text {leaf }_{i}}=N_{m} * L M A * e^{-k_{n} * \frac{L_{i}}{L}} \quad \text { Eq. A2 }
$$

However, the dependence on $L / L$ means that leaf $\mathrm{N}$ decays at a similar rate through the canopy layers for a canopy of leaf area index of 7 as a canopy with leaf area index of 1 . Therefore, in CRM6 leaf $\mathrm{N}$ decays simply as a function of $L_{\mathrm{i}}$ :

$$
N_{\text {leaf }_{i}}=N_{m} * L M A * e_{i}^{-k_{n l} * L_{i}} \quad \text { Eq. A3 }
$$


with a new decay coefficient $\left(k_{\mathrm{nl}}\right)$. When $k_{\mathrm{nl}}=k_{\mathrm{n}} / L$, Eq. A2 and Eq. A3 are equivalent. We use $k_{\mathrm{nl}}=0.2$, which gives the same nitrogen profile as CRM5 when $L=4$.

In both cases, $V_{\mathrm{cmax}, 25}$ for canopy layer $i$ is calculated as a function of $N_{\text {leaf,i. }}$ Plant maintenance respiration is calculated as a function of mean leaf $\mathrm{N}$ throughout the canopy. Prior to JULES4.6 in CRM5, this was incorrectly equal to top-leaf nitrogen:

$\overline{N_{\text {leaf }}}=N_{m} * L M A$

but it is correct in CRM6:

$\overline{N_{\text {leaf }}}=\frac{N_{m} * L M A *\left(1-e^{-k_{n l} * L}\right)}{k_{n l} * L}$

Secondly, new traits from the TRY database were used for calculating root and wood nitrogen, which also affect the total plant maintenance respiration. Equations A6 and A7 were replaced with equations A8 and A9:

$N_{\text {root }}=N_{m} L M A \mu_{r l} * L_{\text {bal }}$

Eq. A6

$N_{\text {stem }}=\frac{N_{m}}{C_{m}} \mu_{s l} \eta_{s l} * h * L_{\text {bal }}$

Eq. A7

where $h$ is the vegetation height in meters, $L_{\text {bal }}$ is the balanced LAI (the seasonal maximum of LAI based on allometric relationships, Cox et al., 2001), $\mu_{\mathrm{rl}}$ and $\mu_{\mathrm{sl}}$ relate $\mathrm{N}$ in roots and stems to top-leaf $\mathrm{N}$, and $\eta_{\mathrm{sl}}$ is $0.01 \mathrm{~kg} \mathrm{C} \mathrm{m}^{-1}\left(\mathrm{~m}^{2}\right.$ leaf) ${ }^{-1}$ (derived from (Friend et al., 1993). $C_{\mathrm{m}}$ is the ratio of carbon per unit biomass $(=0.4)$.

The new equations are:

$N_{\text {root }}=n_{r} * C_{m} * L M A * L_{\text {bal }}$ Eq. A8

$N_{s t e m}=\eta_{s l} * h * L_{b a l} * n_{s w}\left[\frac{1}{a_{w s}}+\left(1-\frac{1}{a_{w s}}\right) * h w_{s w}\right]$ Eq. A9 where Parameters $n_{\mathrm{r}}$ and $n_{\mathrm{sw}}$ were calculated from the TRY database (Table 2). $n_{\mathrm{r}}$ is the ratio of root $\mathrm{N}$ to root $\mathrm{C}, n_{\mathrm{sw}}$ is the ratio of stemwood $\mathrm{N}$ to stem $\mathrm{C}$, and $h w_{\mathrm{sw}}$ is the ratio of stemwood $\mathrm{N}$ to 
heartwood N. The latter is set to 0.5 based on a recommended range of 0.4-0.6 (Hillis, 1987). In all experiments, the maintenance respiration is calculated as:

$R_{p m}=0.012 R_{d}\left(\beta+\frac{N_{r}+N_{s}}{N_{l}}\right)$

where $R_{\mathrm{d}}$ is the leaf dark respiration ( $=V_{\mathrm{cmax}} * f_{\mathrm{d}}$, where $f_{\mathrm{d}}$ is a PFT-dependent parameter) and $\beta$ is the soil moisture stress factor ( 0 for completely stressed plants and 1 for unstressed plants). And the factor 0.012 converts $\mathrm{mol} \mathrm{CO}_{2}$ to $\mathrm{kg} \mathrm{C}$.

The difference between CRM5 and CRM6 is the rate of reduction in leaf $\mathrm{N}$ through the canopy. Since $V_{\text {cmax,i }}$ is proportional to $N_{\text {leaf,i, }}$ it has a more rapid reduction through the canopy in trees if CRM6 is used and LAI $>4$. Total $N_{\text {leaf }}$ is lower in CRM6 than the old (pre-version 4.6) version of CRM5 for all values of LAI (Eq. A5 compared to Eq. A4). Simulated canopy GPP is slightly lower in broadleaf trees in CRM6 due to the difference in total $N_{\text {leaf }}$ but similar for the other PFTs. There is a larger reduction to NPP because the ratio of root and stem $\mathrm{N}$ to leaf $\mathrm{N}$ increases $\left(N_{\text {stem }}\right.$ and $N_{\text {root }}$ are unchanged in Eq. A10), which increases the maintenance respiration for CRM6. Comparing NPP with and without the new N traits, the NPP is higher with the new traits since $N_{\text {stem }}$ and $N_{\text {root }}$ are lower ( $N_{\text {leaf }}$ does not change with the new trait data). The overall effect of both CRM6 and new traits is to reduce plant $\mathrm{N}$ (lower stem and root N) but increase NPP. We further evaluate the impacts of the new $\mathrm{N}$ traits below.

\section{Evaluation}

The nitrogen traits were added to the trunk of JULES4.4, therefore their impacts are evaluated relative to this version of the model. The first set of evaluations are based on 23 FLUXNET sites driven with site meteorology for two years. Canopy radiation model 6 was used with the new 9 PFTs. The vegetation cover for each site was prescribed and there was no competition between the PFTs. 
With the new traits, leaf $\mathrm{N}$ is the same, as expected, except for $\mathrm{C} 3$ and $\mathrm{C} 4$ grass where there are very small differences. The root $\mathrm{N}$ is lower with the new traits for all PFTs. The stem $\mathrm{N}$ is lower for all PFTs except for NET (Figures S1-3). The overall effect of these changes is to increase NPP for all PFTs, since maintenance respiration is proportional to nitrogen content in respiring stemwood and roots. The increase to NPP is greatest for tropical broadleaf evergreen sites (Fig. S4). For grass sites, the increase is relatively higher for C3 grasses. With the grasses, the higher NPP increases the LAI. The NPP doesn't increase LAI for BET because the trees are already at or near the maximum LAI. Maximum LAI is 7 for the BET-Tropical PFT, and 3 for grasses. GPP is unchanged, although eventually there would be a feedback with increased GPP at sites with higher LAI (Fig. S5). On average, the new traits reduce plant respiration and increase NPP and total plant C (Table S1). This results in a global mean NPP of $53 \mathrm{PgC}^{-1}$ and $\mathrm{C}_{\text {veg }}$ of $562 \mathrm{PgC}$.

The relatively higher NPP for C3 grasses and broadleaf trees has implications for the distribution of vegetation. We ran an equilibrium TRIFFID simulation to evaluate the effects on spun-up vegetation. The simulation ran for 65 years using recycled climate from 1901-1920, and using an agricultural fraction from 1860. There is slightly more tropical BET and NDT with the new traits (Fig. S6). C3 grasses cover more area in the tropics and high latitudes, and C4 grasses are less extensive in the tropics. 


\section{References:}

Friend, A. D., Shugart, H. H., and Running, S. W.: A physiology-based model of forest dynamics, Ecology, 74, 792-797, 1993.

Harper, A. B., Cox, P. M., Friedlingstein, P., Wiltshire, A. J., Jones, C. D., Sitch, S., Mercado, L. M., Groenendijk, M., Robertson, E., Kattge, J., Bönisch, G., Atkin, O. K., Bahn, M., Cornelissen, J., Niinemets, Ü., Onipchenko, V., Peñuelas, J., Poorter, L., Reich, P. B., Soudzilovskaia, N. A., and, and Bodegom, P. V.: Improved representation of plant functional types and physiology in the Joint UK Land Environment Simulator (JULES v4.2) using plant trait information, Geosci. Model Dev., 9, 2415-2440, doi.org/10.5194/gmd-9-2415-2016, 2016.

Hillis, W. E.: Heartwood and Tree Exudates, Springer Series in Wood Science, Springer-Verlag Berlin Heidelberg, 268 pp., 1987. 


\begin{tabular}{|l|l|l|}
\hline & Trunk & r2792_N_trait \\
\hline GPP (Pg C/yr) & 124 & 123 \\
\hline Plant Resp (Pg C/yr) & 78 & 70 \\
\hline NPP (Pg C/yr) & 46 & 53 \\
\hline Cveg (Pg C) & 498 & 562 \\
\hline
\end{tabular}

Table 1. Comparison of global carbon cycle metrics with and without the new $\mathrm{N}$ traits for presentday. 


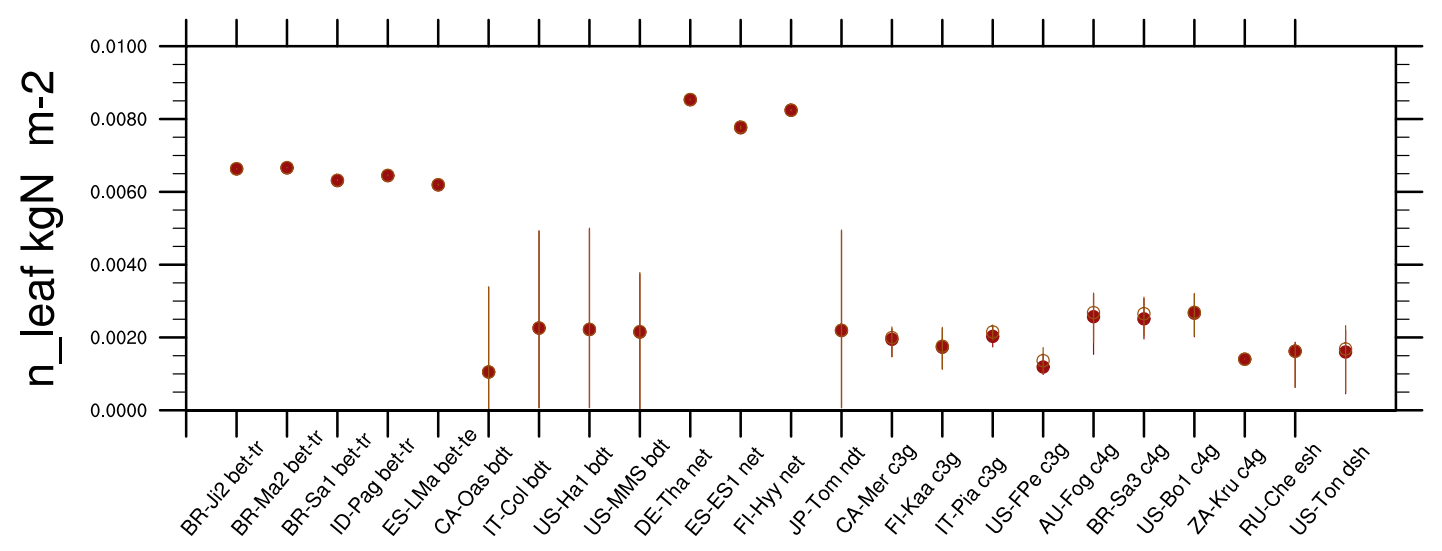

Figure S1. Average N content of leaves for each site. Red is default (based on JULES4.4 Trunk before the new $\mathrm{N}$ traits were added) and Orange is the branch with the new N traits (r2792_N_trait). The vertical lines show the seasonal minimum and maximum values, which distinguishes the deciduous and evergreen sites.

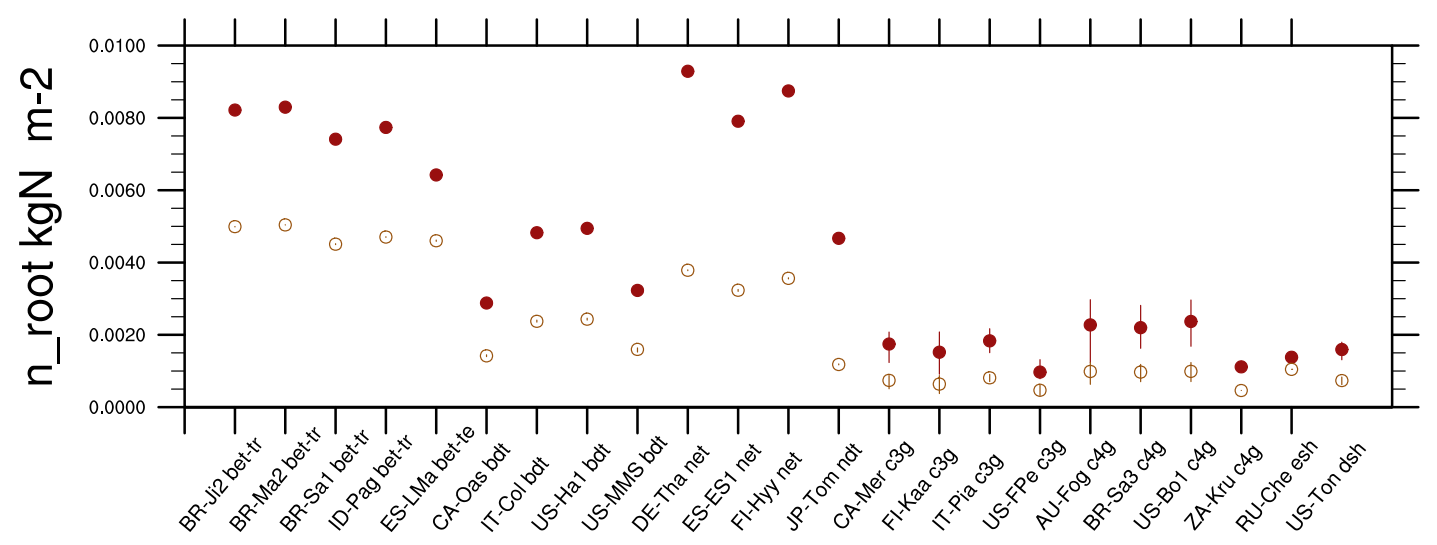

Figure S2. As in Fig. S1 but for root N. Red is default and Orange is with the new N traits. 


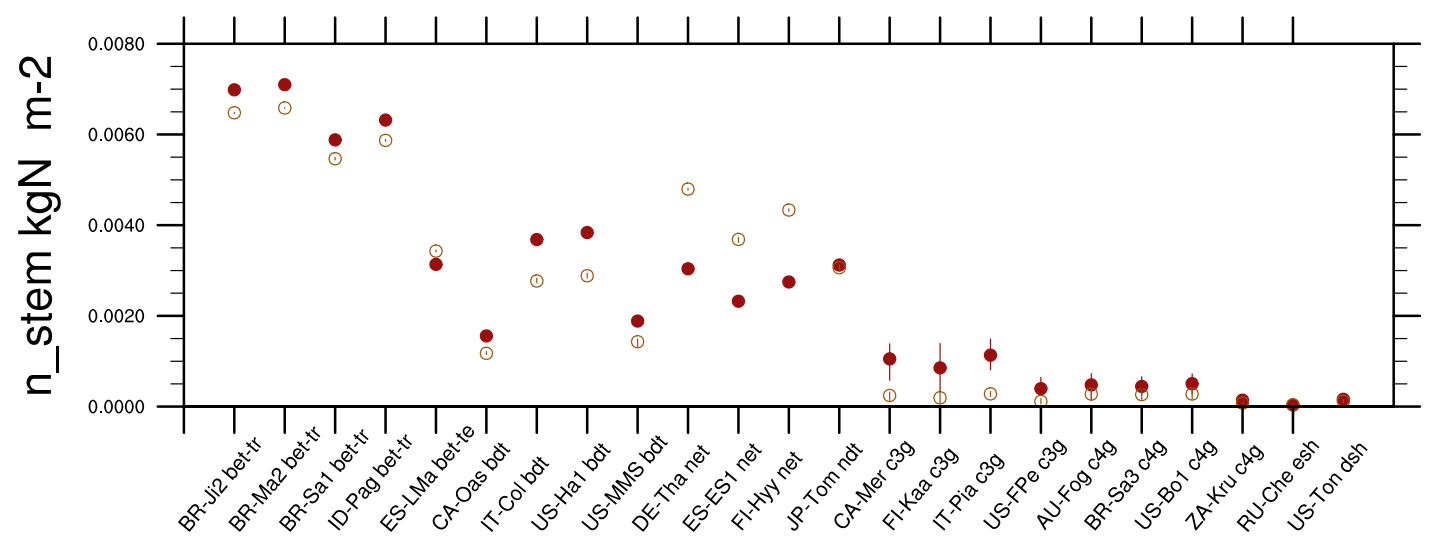

Figure S3. As in Fig. S1 but for nitrogen in respiring stemwood. Red is default and Orange is with the new $\mathrm{N}$ traits. 

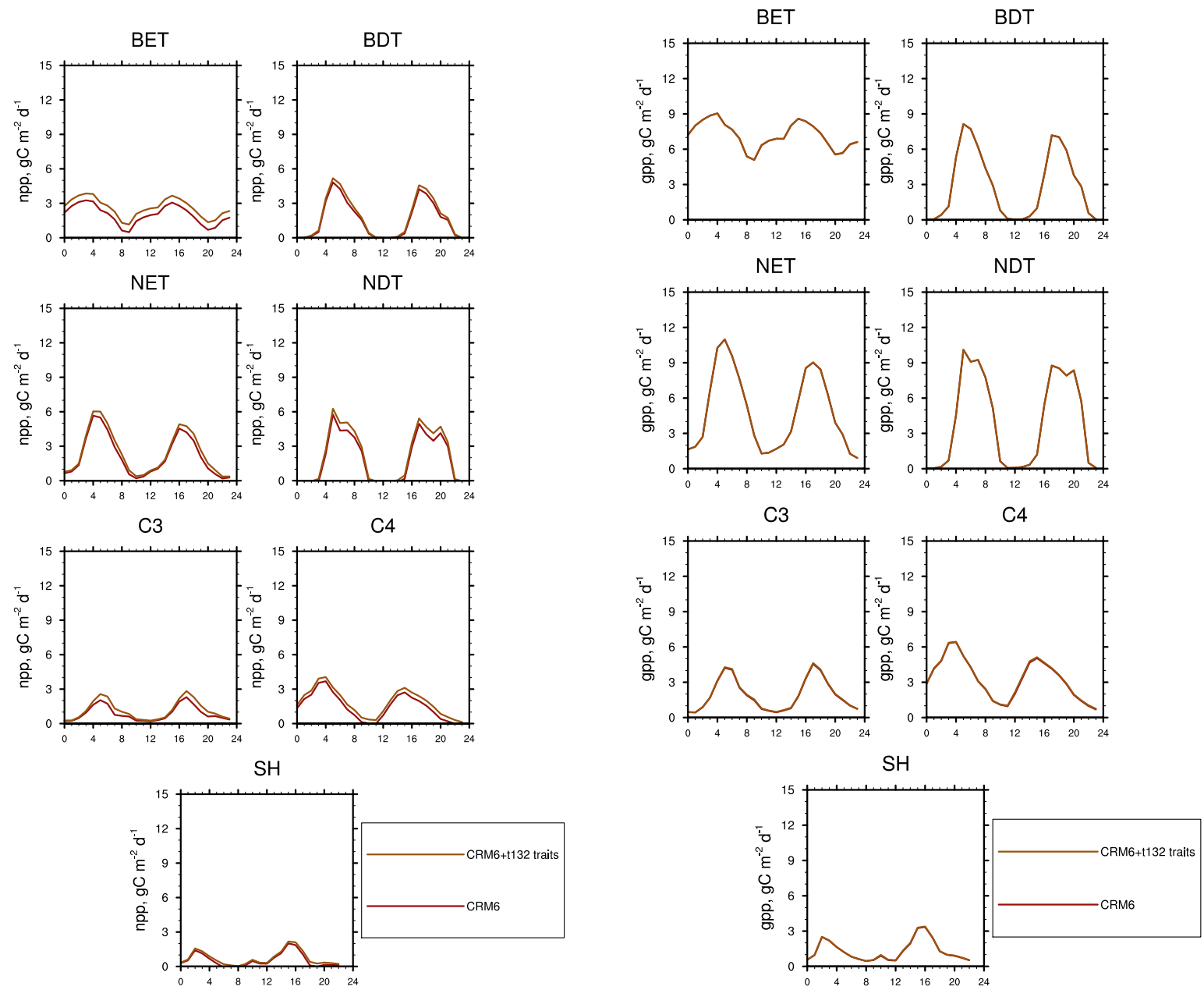

Figure S4. Monthly mean gross primary productivity (GPP) and net primary productivity (NPP) in the 23 FLUXNET sites, grouped according to their dominant PFT. 


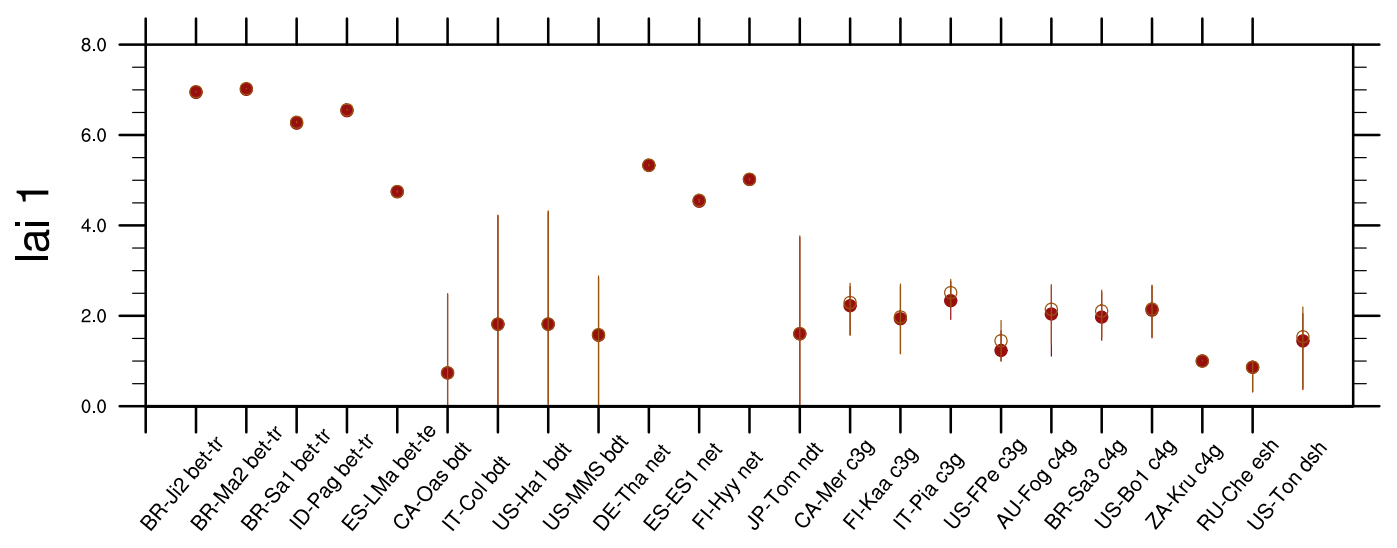

Figure S5. As in Fig. S1 but for leaf area index (LAI). Red is default and Orange is with the new N traits. 
BET-Tr: JULES4.4 trunk

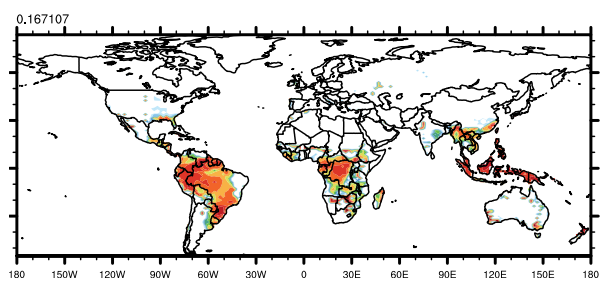

C3 grass: JULES4.4 trunk

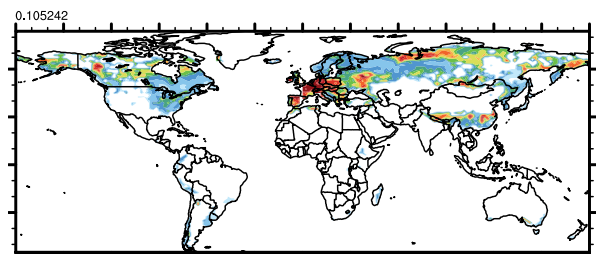

C4 grass: JULES4.4 trunk

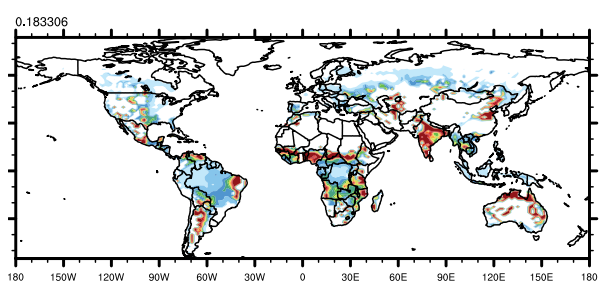

BET-Tr: vn4.4 with $\mathrm{N}$ traits

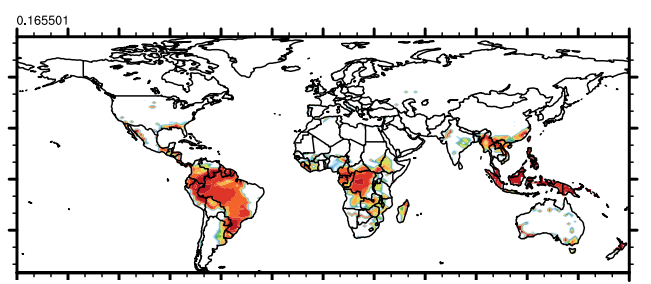

C3 grass: vn4.4 with $\mathrm{N}$ traits

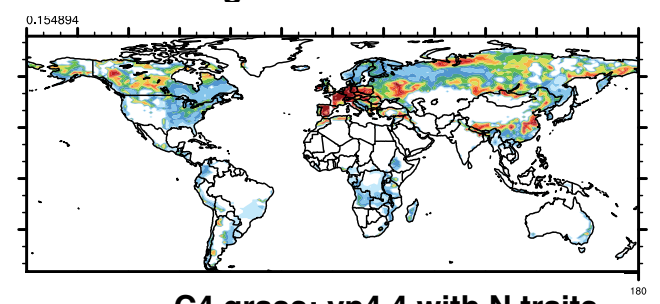

C4 grass: vn4.4 with $\mathrm{N}$ traits

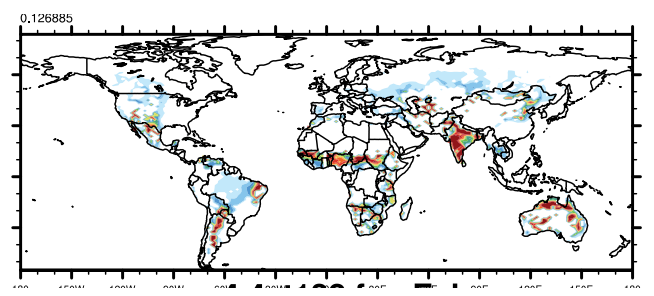

Figure S6. Fractional coverage of PFTs where new $\mathrm{N}$ traits for roots and stems caused a difference in distribution (BET-Tr= tropical broadleaf evergreen trees). The new traits primarily reduced maintenance respiration and increased NPP. The change is greatest for tropical trees and C3 grass, hence the increased factional coverage of these two PFTs at the expense of $\mathrm{C} 4$ grass. 

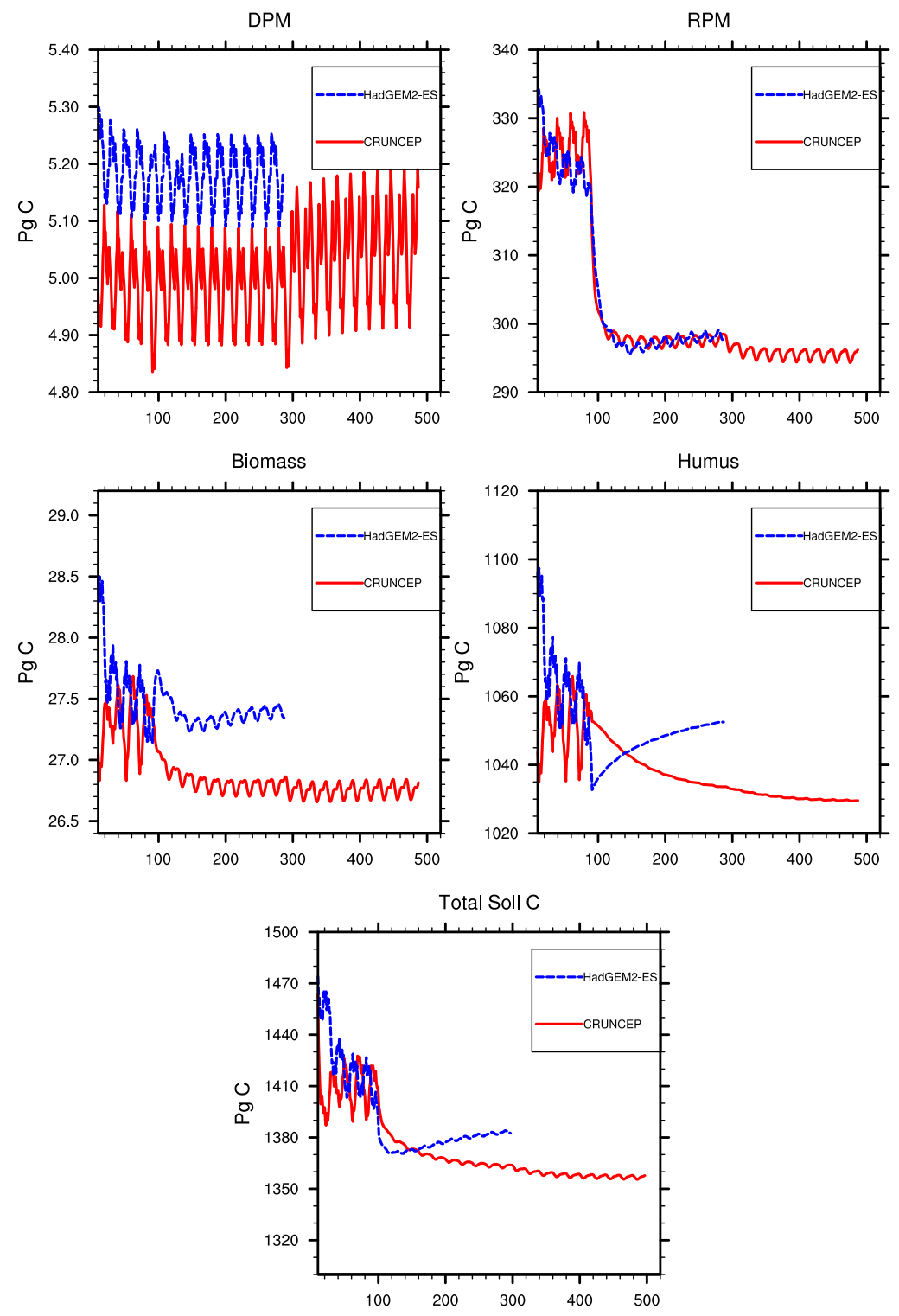

Figure S7. Total soil carbon in JULES-C2 during the spin up period (bottom panel). The top four panels are the individual soil carbon pools (DPM = decomposable plant material; RPM = resistant plant material). Years 1-80 use the accelerated turnover times. Then JULES-C2 was spun up with default turnover times for an additional 200 years with the HadGEM2-ES climate, and for 400 years with the CRUNCEP climate (to allow for adjustment to a new version of CRUNCEP data). See Table 3 for turnover times of the four soil carbon pools in the two phases of spin up. 

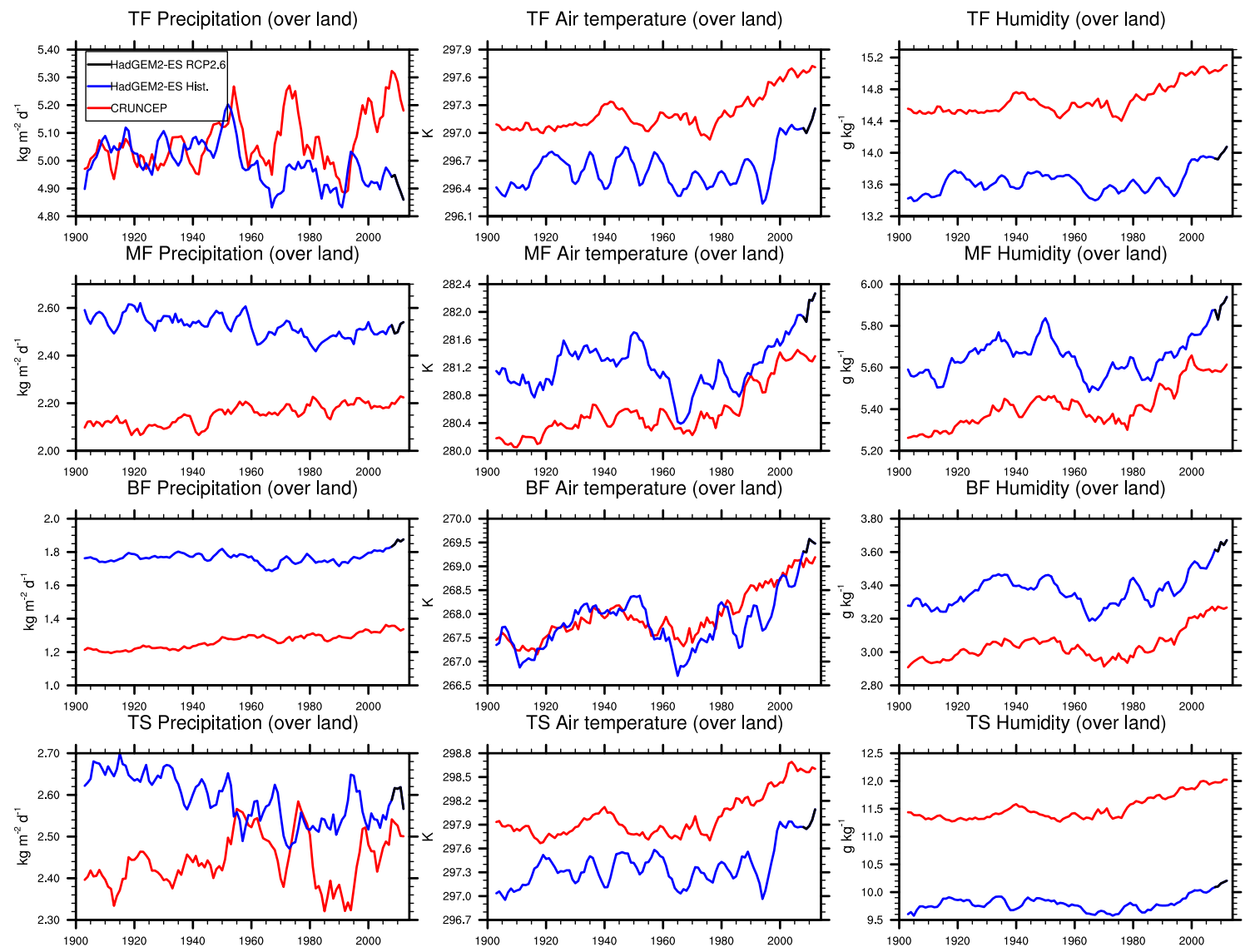

Figure S8. Annual average climate for HadGEM2-ES and CRUNCEPv6 climates for the eight biomes (TF=tropical forests; MF=mixed forests; $\mathrm{BF}=$ boreal forests; $\mathrm{TS}=$ tropical savannah) shown in Figure SM 9. 

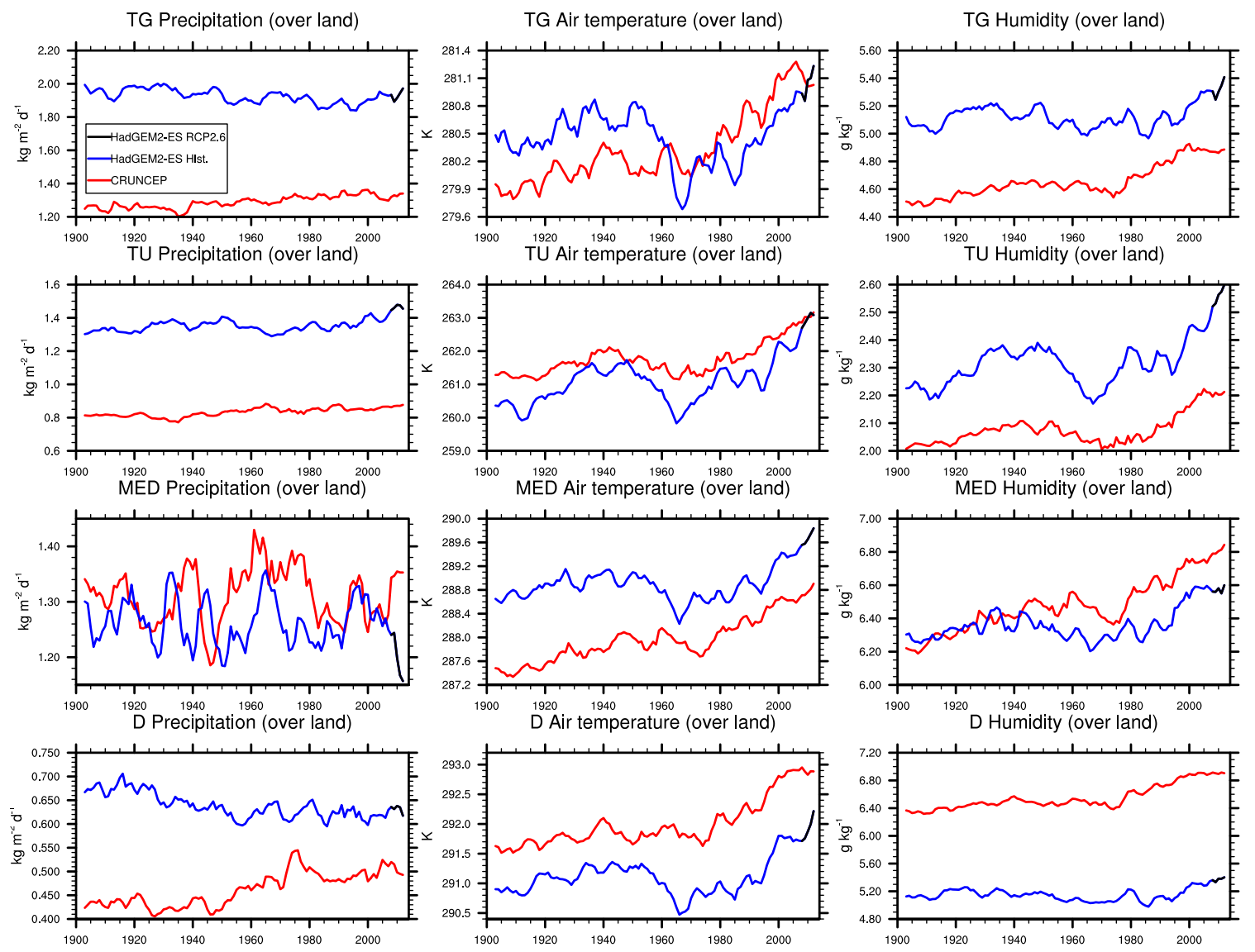

Figure S8, continued. Biomes: $\mathrm{TG}=$ temperate grasslands; $\mathrm{TU}=$ tundra; $\mathrm{MED}=$ Mediterranean woodlands; $\mathrm{D}=$ deserts 


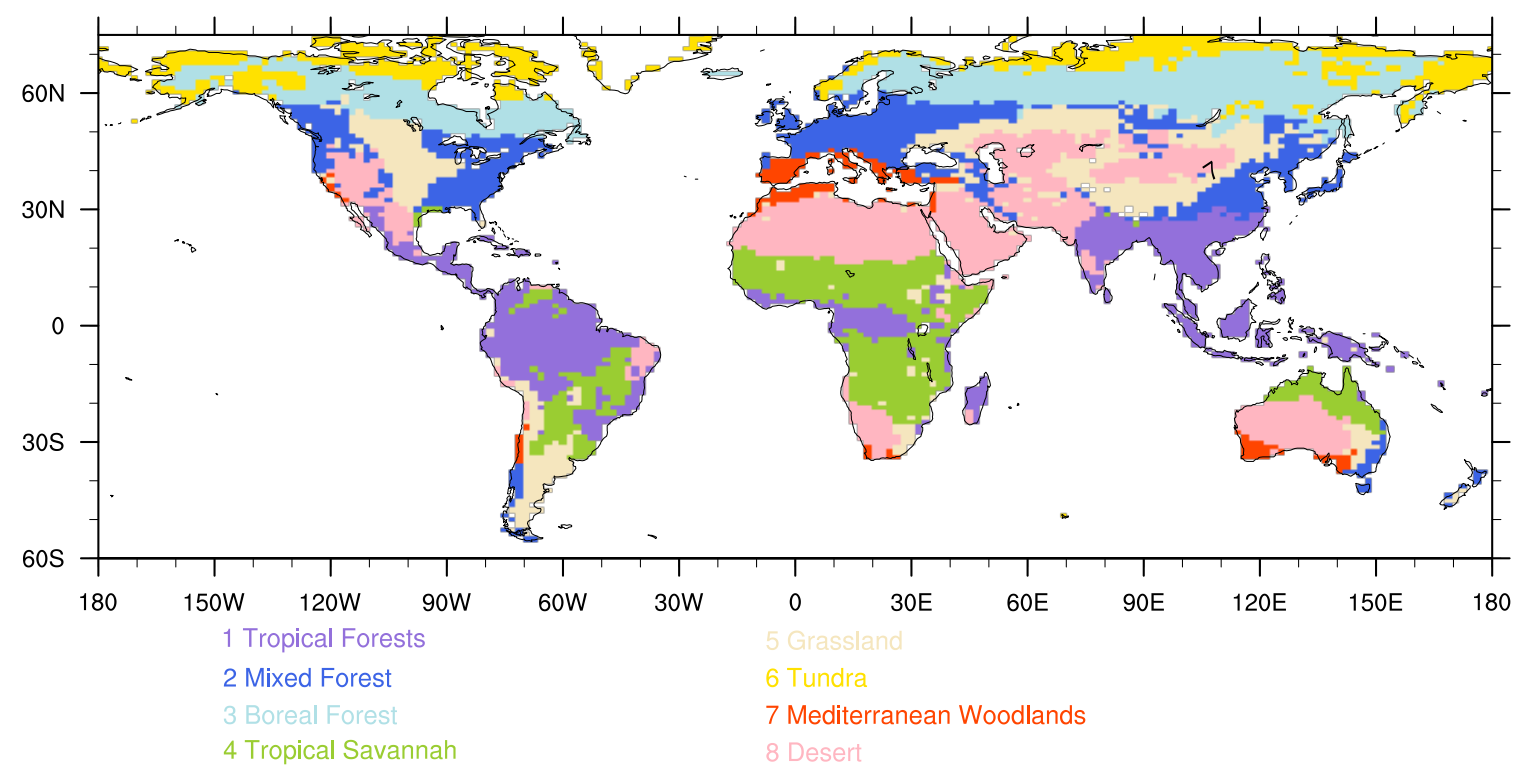

Figure S9. Major global biomes based on the 14 World Wildlife Fund's ecoregions. Some ecoregion were combined to reduce the total number to 8: Tropical forests $=$ all tropical and subtropical forests plus mangroves; Mixed forest = temperate broadleaf and mixed forests plus temperate conifer forests; tropical savannahs = tropical/sub-tropical grasslands, savannah, and shrubland; Grassland = temperate grasslands, savannahs, shrublands, flooded grasses, montane grasses. 
a) GPP $\left(\mathrm{Pg} \mathrm{C} \mathrm{y}^{-1}\right)$

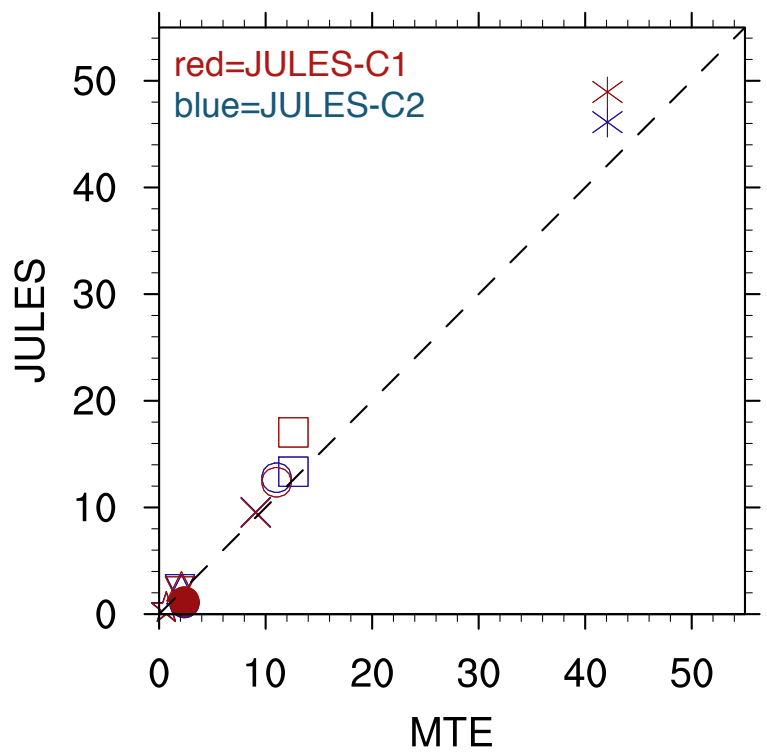

c) $\mathrm{C}_{\text {veg }}(\mathrm{Pg} \mathrm{C})$

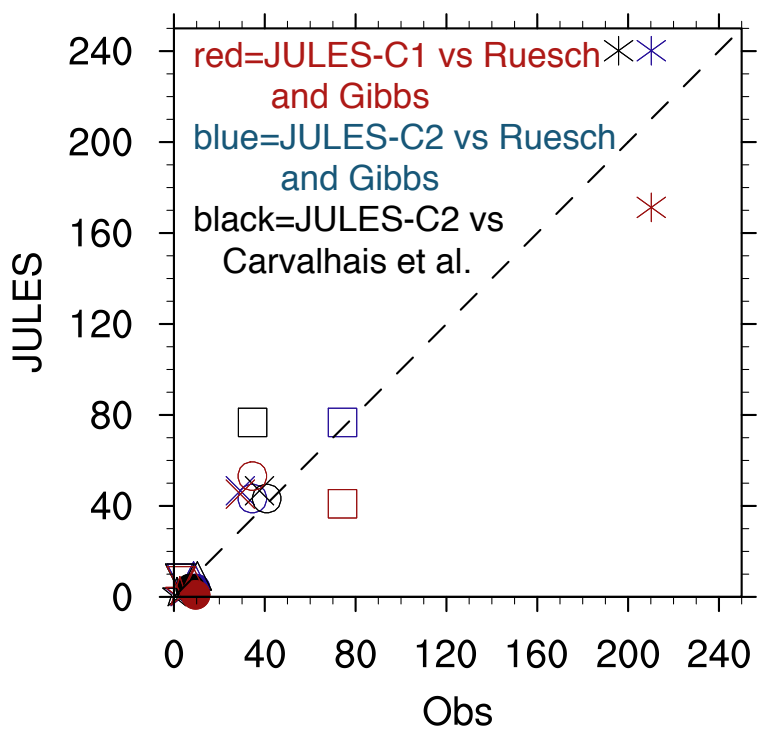

b) NPP $\left(\mathrm{Pg} \mathrm{C} \mathrm{y}^{-1}\right)$

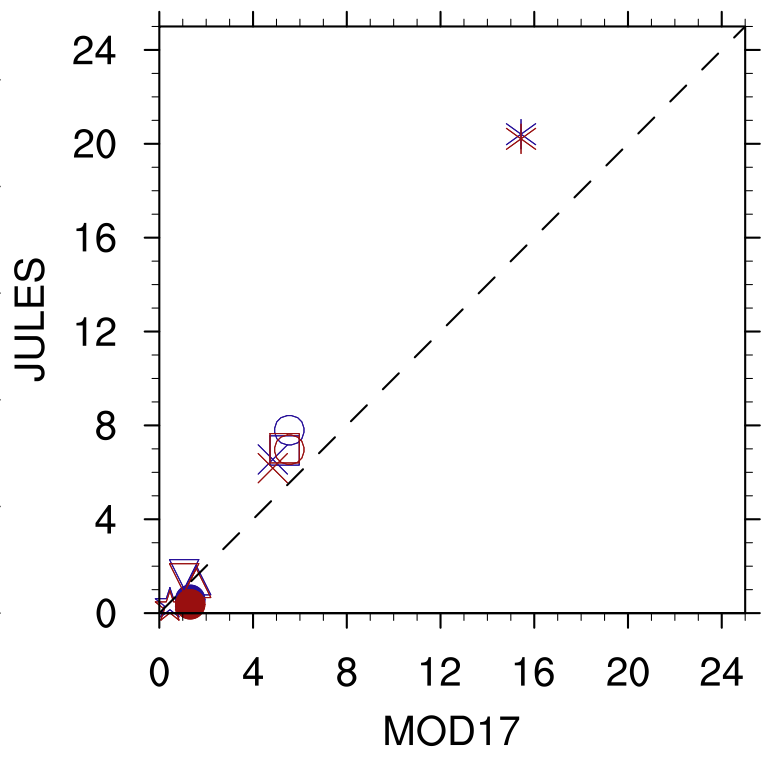

d) $\mathrm{C}_{\text {soil }}(\mathrm{Pg} \mathrm{C})$

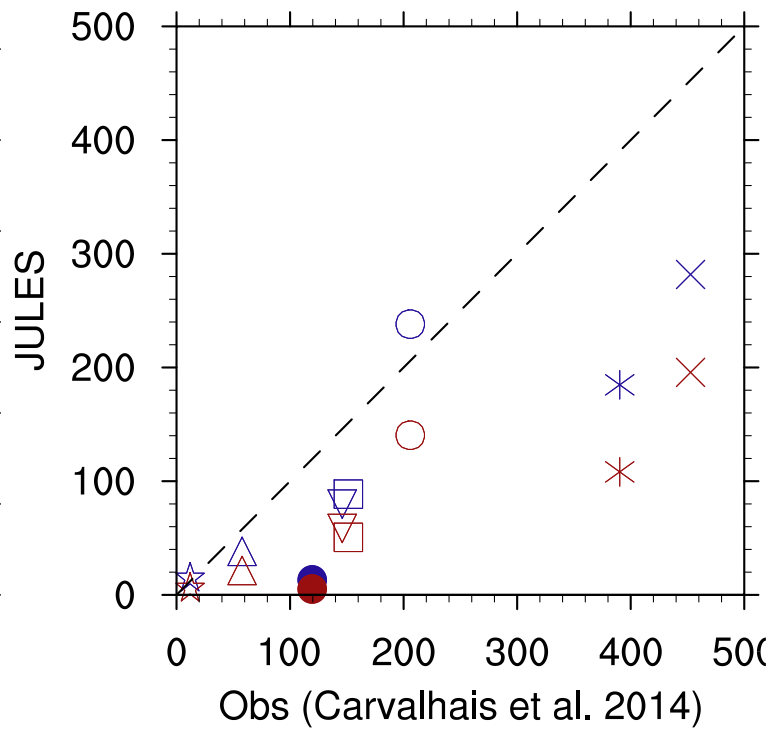

Figure S10. For comparison with Figure 4. Biome-averaged (a) GPP, (b) NPP, (c) $\mathrm{C}_{\text {veg, }}$, and (d) $\mathrm{C}_{\text {soil }}$ in JULES-C1 vn4.2 with CRUNCEP-v4 climate, and JULES-C2 (with CRUNCEP-v6 climate) compared to observations. The observation sources are the same as in Fig. 3 except (c) includes the $\mathrm{C}_{\text {veg }}$ from Carvalhais et al. (2014) (black shapes). The biomes are TF: Tropical Forests; MF: Temperate Mixed Forests; BF: Boreal Forests; TS: Tropical Savannah; TG:

Temperate Grasslands; TU: Tundra; MED: Mediterranean Woodlands; D: Deserts (biomes in Fig. SM8). Grid cells with $>50 \%$ agriculture have been excluded from the biome averages. 